Jonel Donn Leo S. Gloria, MD, MOH

Alfredo Quintin Y. Pontejos, Jr., MD

Precious Eunice R. Grullo, MD, MPH

Department of Otorhinolaryngology

University of the Philippines - Philippine General Hospital
Correspondence: Dr. Alfredo Quintin Y. Pontejos, Jr.

Department of Otorhinolaryngology

Ward 10, Philippine General Hospital

University of the Philippines, Manila

Taft Avenue, Ermita, Manila 1000

Philippines

Phone: (632) 5548400 local 2152

Email: docpontejosjr@yahoo.com

The authors declare that this represents original material, that the manuscript has been read and approved by all the authors, that the requirements for authorship have been met by each author, and that each author believes that the manuscript represents honest work.

Disclosures: The authors signed disclosures that there are no financial or other (including personal) relationships, intellectual passion, political or religious beliefs, and institutional affiliations that might lead to a conflict of interest

Presented at the Philippine Society of Otolaryngology Head and Neck Surgery Analytical Research Contest (1st Place), November 17, 2016. Bella Ibarra, Quezon Avenue, Quezon City.

\section{Risk Factors for Recurrent Papillary Thyroid Carcinoma}

\section{ABSTRACT}

Objective: To identify risk factors associated with disease recurrence among Filipinos with papillary thyroid carcinoma (PTC).

\section{Methods:}

$\begin{array}{ll}\text { Design: } & \text { Retrospective Cohort Study } \\ \text { Setting: } & \text { Tertiary National University Hospital } \\ \text { Participants: } & 76 \text { patients diagnosed with papillary thyroid carcinoma, classified as }\end{array}$ low and low-to-intermediate risk (2015 ATA classification) that underwent total thyroidectomy with or without neck dissection from 2010-2014 and were followed up from 10 months to 5 years. Log rank and Cox regression analyses were used to determine significant risk factors for recurrence.

Results: 29 (38.15\%) had recurrence. On univariate analysis, age, tumor size, multifocality, extrathyroidal extension, presence of lateral neck nodes and RAI therapy were statistically associated with recurrence. However, on multivariate analysis, no clinicopathologic factor was statistically associated with recurrence.

Conclusion: Age of $>45$ years, female sex, tumor size of $>2 \mathrm{~cm}$, multifocality, presence of microscopic extrathyroidal extension and lymph node metastasis might contribute to the recurrence of papillary thyroid cancer while post-operative radioactive ablation may have some protective effect. However, this study suggests that other factors must be included in the model to better understand the relationship between these factors and recurrence.

Keywords: papillary thyroid cancer, thyroid neoplasm, recurrence

Thyroid cancer was the most frequent head and neck cancer in the Philippines in $2012^{1}$ and continues to rank among the most common reasons for admission at the Philippine General Hospital-Department of Otorhinolaryngology (PGH-ORL). A review of all thyroid cases admitted at the PGH-ORL from January 2006 to December 2010 revealed 415 thyroid malignancies managed, of which $82.9 \%$ were papillary thyroid carcinoma (PTC). ${ }^{2}$ 


\section{ORIGINAL ARTICLES}

The primary treatment of PTC is still surgery (thyroidectomy) and when appropriate, a neck dissection. ${ }^{3,45}$ In our setting, a considerable subset of PTC tends to become more aggressive and recurs even with adequate surgical and medical management. While local and regional recurrences of PTC after surgery have ranged from 5-10\%, ${ }^{6}$ a 2010 study among Filipinos with thyroid cancer claimed recurrence rates as high as $25 \%{ }^{7}$ Recurrences may be local (primary site and adjacent structures), regional (cervical lymph nodes) or distant and impact negatively on patients' quality of life with increased morbidity.

The extent of surgery and need for adjuvant treatment depend on several prognostic factors that influence risk stratification of patients in terms of recurrence and survival. Several studies have identified clinicopathologic factors predictive of increased risk of recurrence among patients with PTC, including age, sex, tumor size, cervical lymph node metastasis, extrathyroidal invasion, bilaterality/multifocality and post-operative RAI therapy. ${ }^{8-17}$

In order to determine specific patient- and disease-related factors associated with PTC recurrence among our patient population that are essential for developing initial treatment and follow-up schemes and establishing the need for adjuvant treatment in our setting, this study aims to determine factors that are associated with recurrence of PTC among patients admitted at PGH-ORL in terms of age during initial surgery, sex, tumor size, multifocality, extrathyroidal extension, lymph node metastasis and post-operative RAI therapy.

\section{METHODS}

With institutional review board approval, this retrospective cohort study reviewed the records of 86 patients diagnosed with papillary thyroid carcinoma that underwent total thyroidectomy with or without neck dissection at the PGH-ORL from January 2010 to December 2014 and followed up for at least 10 months. Papillary thyroid carcinoma recurrence was defined as the reappearance of PTC after a period of at least 10 months from initial surgery including both local and regional recurrences. ${ }^{7}$

Medical records (including operative records and histopathology results) were reviewed for the following data: age (years) at the time of initial surgery, sex, tumor size, multifocality, extrathyroidal extension, lymph node metastasis, post-operative RAl therapy and length of follow-up. Considered for inclusion were records of patients with Papillary Thyroid Cancer on histopathologic result and low and lowto-intermediate risk 2015 ATA classification. Excluded were records of cases with no definite histopathologic result and high-risk 2015 American Thyroid Association (ATA) classification (residual disease, gross extrathyroidal extension, distant metastasis) as these patients had high risk of recurrence. ${ }^{18}$

Data was tabulated using Microsoft Excel version 2013 (Microsoft, (hicago, USA) and means and proportions were obtained. Univariate analysis was performed using log-rank test. The outcome of interest was recurrence, established by imaging (ultrasonography or computed tomography), thyroglobulin levels, thyroid scintigraphy, or histopathology. Variables with $p<.25$ on univariate analysis were included in the multivariate analysis using Cox regression. KaplanMeier curves were obtained. Data were analyzed using STATA version 13.1 (StataCorp, TX, USA).

\section{RESULTS}

Records of 76 patients ( 21 males, 55 females) were included in this series. The mean age of the patients was $44 \pm 2$ years (range 15-77 years). The average tumor size was $3.96 \pm 0.29 \mathrm{~cm}$ (range 0.3 to $14.5 \mathrm{~cm}$ ). 29 (38.15\%) had recurrences while 47 had no observed recurrence on the cut-off date. The sites of recurrences follows: 3 , thyroid bed only; 17 , lateral neck (16 unilateral and 1 bilateral); 9 , both thyroid bed and lateral neck ( 6 in the thyroid bed and unilateral neck and 3 in the thyroid bed and bilateral neck). The 10 excluded records were those of 2 patients that had no definite histopathologic result and 8 cases with high risk 2015 ATA classification. Table 1 summarizes the clinicopathologic profiles of the patients included in the series.

With cut-off $p<.25$, age $(p=.01)$, tumor size $(p=.2)$, multifocality ( $p$ $=.04)$, extrathyroidal extension $(p=.02)$, presence of lateral neck nodes $(p=.03)$ and RAI therapy $(p=.2)$ were included in multivariate analysis on which no clinicopathologic factor was statistically associated with recurrence. This indicates that other factors affecting recurrence are missing in the model $\left(R^{2}=0.3776\right)$. Table 2 summarizes the results ( $p$ values, hazards ratios and confidence intervals) of both univariate and multivariate logistic regression analyses on the factors studied.

In this study, those with age $>45$ years old had 1.93 times higher risk of having a recurrence than those $</=45$ years old . Tumor size of $>2$ to 4 $\mathrm{cm}$ and $>4 \mathrm{~cm}$ had $59 \%$ and $74 \%$ increased risk of recurrence compared to tumors $<2 \mathrm{~cm}$ in size, respectively. The presence of multifocality increased the risk of recurrence by $69 \%$. The risk of recurrence was 1.31 times higher if extrathyroidal extension was present. Unilateral neck nodes and bilateral neck nodes increased the risk of recurrence 2.06 times and 1.47 times, respectively. RAl therapy decreased the risk of recurrence by $51 \%$. Figure 1 shows the Kaplan-Meier curve analysis for each clinicopathologic factor studied. The estimated 5-year recurrencefree estimate is $32.87 \%$. 
Table 1. Clinicopathologic profile of the patients

\begin{tabular}{|c|c|c|c|}
\hline \multicolumn{2}{|c|}{ Clinicopathologic factors } & $\begin{array}{l}\text { Without } \\
\text { recurrence } \\
n=47\end{array}$ & $\begin{array}{c}\text { With } \\
\text { recurrence } \\
\mathbf{n}=\mathbf{2 9}\end{array}$ \\
\hline \multirow[t]{2}{*}{ Age (years) } & $\leq 45$ & $28(60 \%)$ & $11(38 \%)$ \\
\hline & $>45$ & $19(40 \%)$ & $18(62 \%)$ \\
\hline \multirow[t]{2}{*}{ Sex } & male & $14(30 \%)$ & $7(24 \%)$ \\
\hline & female & $33(70 \%)$ & $22(76 \%)$ \\
\hline \multirow[t]{3}{*}{ Tumor Size (cm) } & $\leq 2$ & $17(36 \%)$ & $7(24 \%)$ \\
\hline & $>2$ to 4 & $16(34 \%)$ & $6(21 \%)$ \\
\hline & $>4$ & $14(30 \%)$ & $16(55 \%)$ \\
\hline \multirow[t]{2}{*}{ Multifocality } & absent & $32(68 \%)$ & $12(41 \%)$ \\
\hline & present & $15(32 \%)$ & $17(59 \%)$ \\
\hline \multirow{2}{*}{$\begin{array}{l}\text { Extrathyroidal } \\
\text { extension }\end{array}$} & absent & $38(81 \%)$ & $11(38 \%)$ \\
\hline & present & $9(19 \%)$ & $18(62 \%)$ \\
\hline \multirow{2}{*}{$\begin{array}{l}\text { Central neck } \\
\text { nodes }\end{array}$} & absent & $33(70 \%)$ & $21(72 \%)$ \\
\hline & present & $14(30 \%)$ & $8(28 \%)$ \\
\hline \multirow{3}{*}{$\begin{array}{l}\text { Lateral neck } \\
\text { nodes }\end{array}$} & absent & $32(68 \%)$ & $14(48 \%)$ \\
\hline & unilateral & $14(30 \%)$ & $12(41 \%)$ \\
\hline & bilateral & $1(2 \%)$ & $3(11 \%)$ \\
\hline \multirow[t]{2}{*}{ RAI therapy } & absent & $20(43 \%)$ & $19(66 \%)$ \\
\hline & present & $27(57 \%)$ & $10(34 \%)$ \\
\hline $\begin{array}{l}\text { Follow-up time } \\
\text { (months) }\end{array}$ & & 30 (sd:3) & 32 (sd:4) \\
\hline
\end{tabular}

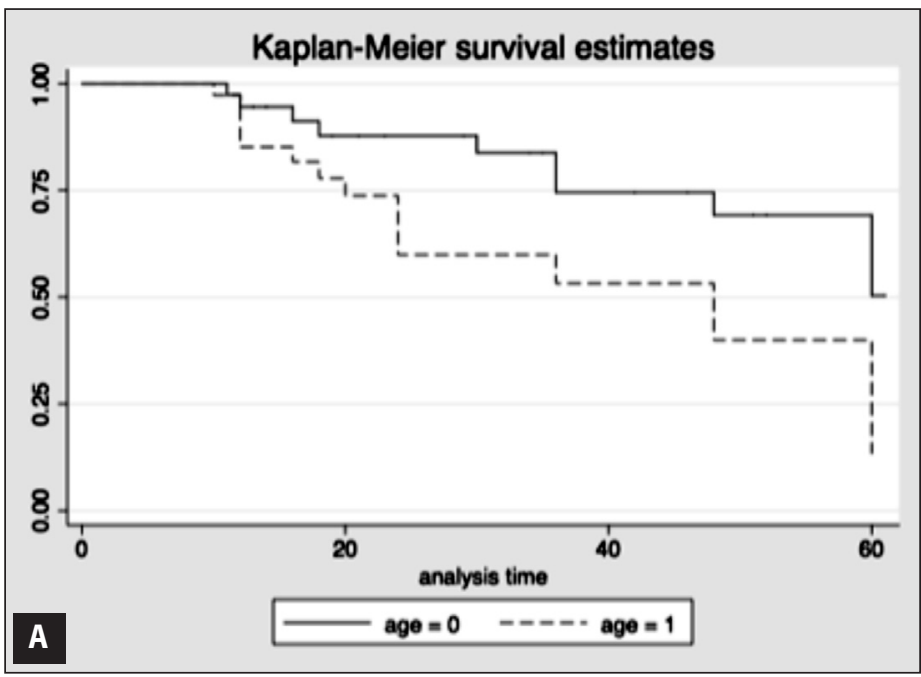

Table 2. Univariate and multivariate analyses of the factors associated with PTC recurrence

\begin{tabular}{|c|c|c|c|c|c|}
\hline \multicolumn{2}{|c|}{ Clinicopathologic Factors } & \multirow{2}{*}{ 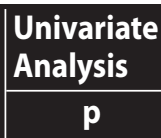 } & \multicolumn{3}{|c|}{ Multivariate Analysis } \\
\hline & & & HR & $\mathbf{C l}$ & $\mathbf{p}$ \\
\hline Age & $\leq 45$ & .01 & 1.93 & $0.78-4.80$ & .10 \\
\hline Sex & female & .27 & & & \\
\hline \multirow[t]{2}{*}{ Tumor Size } & $>2$ to 4 & .20 & 1.59 & $0.49-5.24$ & .44 \\
\hline & $>4$ & & 1.74 & $0.68-4.48$ & .25 \\
\hline Multifocality & present & .04 & 1.69 & 0.71-4.04 & .25 \\
\hline $\begin{array}{l}\text { Extrathyroidal } \\
\text { extension }\end{array}$ & present & .02 & 1.31 & $0.56-3.1$ & .53 \\
\hline $\begin{array}{l}\text { Central neck } \\
\text { nodes }\end{array}$ & present & .74 & & & \\
\hline \multirow{2}{*}{$\begin{array}{l}\text { Lateral neck } \\
\text { nodes }\end{array}$} & unilateral & \multirow[t]{2}{*}{.03} & 2.06 & 0.83-5.1 & .12 \\
\hline & bilateral & & 1.47 & $0.33-6.47$ & .61 \\
\hline RAl therapy & present & .20 & 0.49 & $0.21-1.15$ & .10 \\
\hline
\end{tabular}

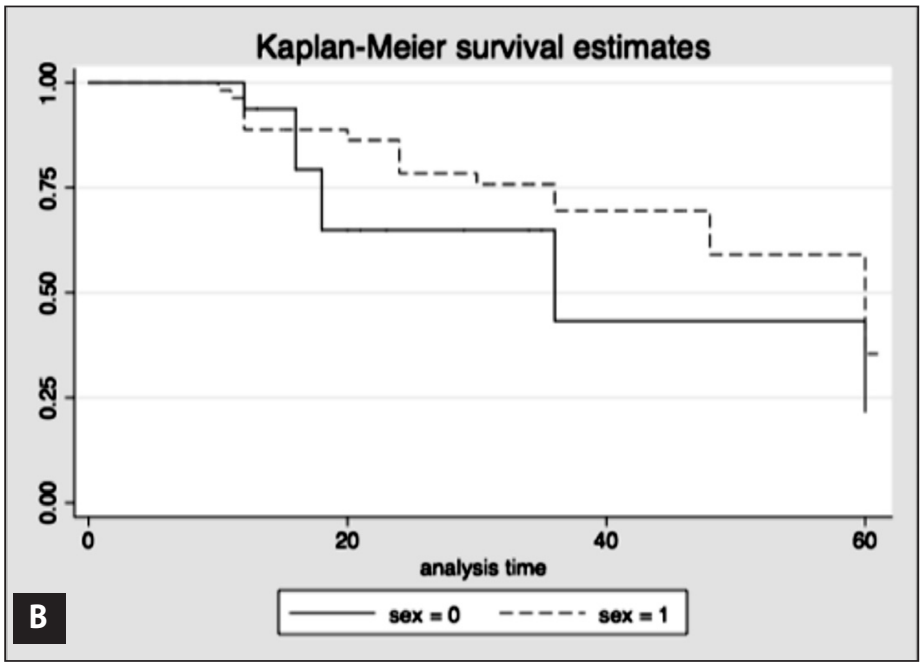

Note: Blacked out cells are not included in the multivariate analysis; cut-off $p<0.25$

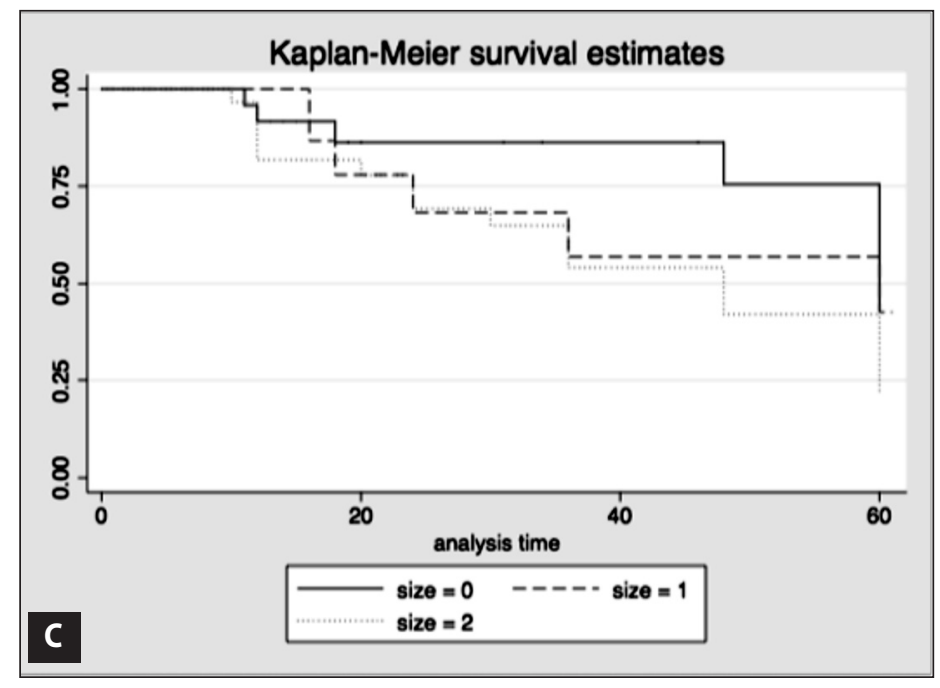



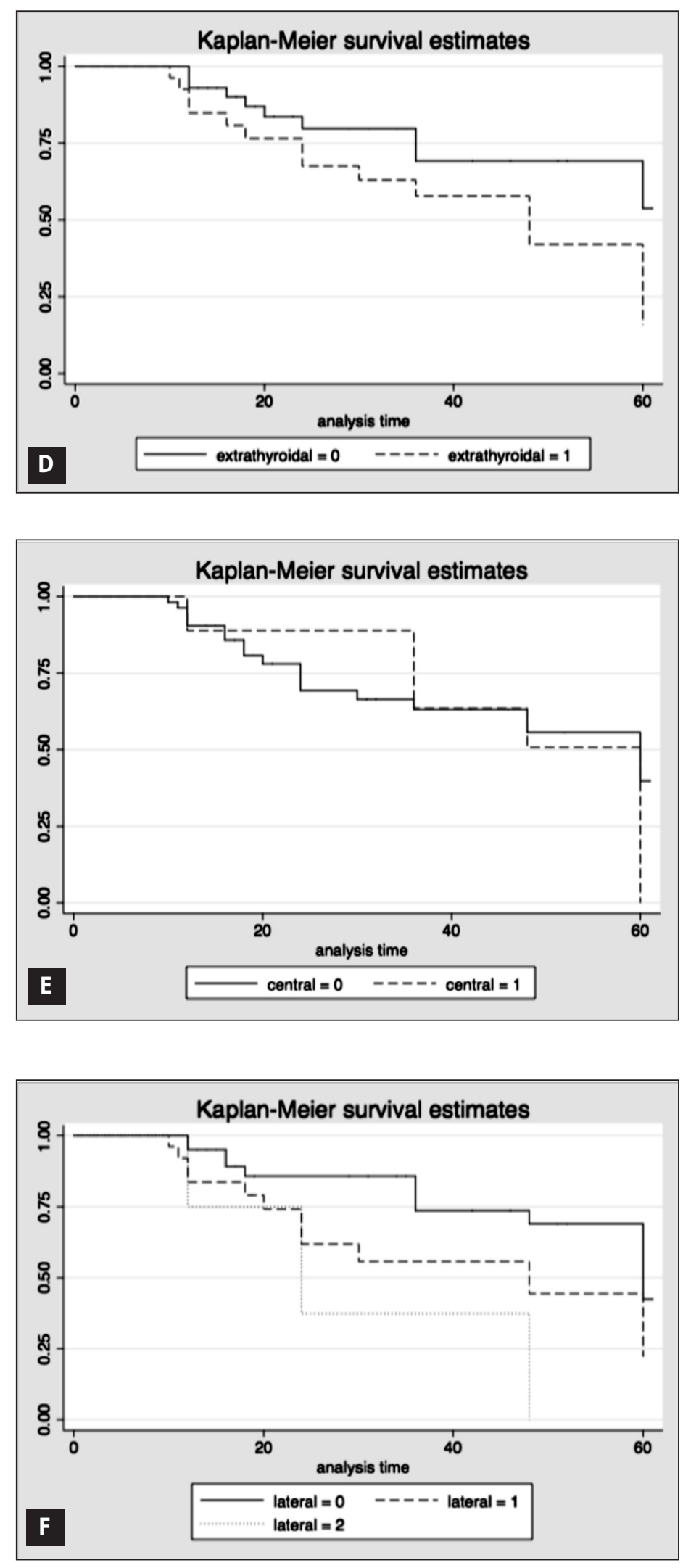
of recurrence and significantly decreased disease-free survival in PTC patients with macroscopic extrathyroidal extension ${ }^{21}$ and nodal metastasis has been reported to increase the risk of recurrence. ${ }^{19,21}$

The use of post-operative RAl therapy based on our results is protective with an HR of 0.49 . Unlike in high risk patients where the evidence for the benefits of RAI are strong, the ATA 2015 guideline reported that there are conflicting observational data in the use of postop RAl among low and low-to intermediate risk patients. ${ }^{18}$ According to the UP-PGH Revised Clinical Practice Guidelines for the Management of Well-Differentiated Thyroid Carcinoma of Follicular Cell Origin in 2012, the use of adjuvant RAI treatment in well-differentiated thyroid cancer has been shown to significantly decrease disease recurrence and causespecific mortality. ${ }^{5}$ Our study supports this recommendation.

There are several limitations of this study. First is the potential for selection bias in a retrospective study. In this study, it was assumed that all tumors were resected if no residual tumor was indicated in the operative technique or no positive margins were noted on histopathologic result. Initial thyroglobulin levels were not available for all patients. Second, the timing of recurrence is relative. For some patients, recurrence was detected due to regular determination of thyroglobulin. For some, imaging was done after a neck mass was noted. In effect, the diagnosis of recurrence might be later than it really is. This could decrease the possible relationship of recurrence to the variables studied. Third, the variables measured in this study were limited to age (years) at the time of initial surgery, sex, tumor size, multifocality, microscopic extrathyroidal extension, lymph node metastasis and post-operative RAl therapy. Other variables that could affect recurrence like molecular mutation status and timeliness of RAI therapy were not measured.

In conclusion, age of $>45$ years, female sex, tumor size of $>2 \mathrm{~cm}$, multifocality, presence of microscopic extrathyroidal extension and lymph node metastasis might contribute to the recurrence of papillary thyroid cancer while post-operative radioactive ablation may have some protective effect. However, the findings in this study suggest that other factors must be included in the model in order to better understand the relationship between these factors and recurrence.

\footnotetext{
REFERENCES

1. World Health Organization. GLOBOCAN 2012: Estimated cancer incidence, mortality and prevalence worldwide in 2012. [cited 2014 Jan 12]. Available from: : http://globocan.iarc.fr/ Pages/fact sheets cancer.aspx.

2. Holgado J, Gloria J, Pontejos A. Epidemiologic study of thyroid lesions treated in the Philippine General Hospital - Department of Otorhinolaryngology: A 5-year experience. In press 2012.

3. Pontejos A, Caparas M, Cabungcal A, Hardillo J, Hernandez J, Hernandez M, et al. Manual for the Management of Head and Neck Malignancies, $2^{\text {nd }}$ Edition. 2012, p 59-65.

4. National Comprehensive Cancer Network Clinical Practice Guidelines in Oncology, Head and Neck Cancers, Version 1.2015. [accessed 2015 Jan 13]. Available from: http:// oralcancerfoundation.org/wp-content/uploads/2015/09/head-and-neck.pdf.

5. Sison CM, Obaldo J, Matsuo J, Uy GM, Jaring C. University of the Philippines - Philippine General Hospital Revised Clinical Practice Guidelines for the Management of Well-Differentiated Thyroid Carcinoma of Follicular Cell Origin. Journal of the ASEAN Federation of Endocrine Societies. 2012 May; 27(1):49-61. DOI: https://doi.org/10.15605/jafes.027.01.08.

6. Schlumberger M. Papillary thyroid carcinoma. Orphanet encyclopedia. 2004. [cited 2014 Feb 2]. Available from: http://www.orpha.net/data/patho/GB/uk-PTC.pdf.

7. Kus L, Shah M, Eski S, Walfish P, Freeman J. Thyroid cancer outcomes in Filipino patients. 2010. [cited 2014 Jan 23]. Available from: http://archotol.jamanetwork.com.

8. Popadich A, Levin O, Lee JC, Smooke-Praw S, Ro K, Fazel M, et al. A multicenter cohort study of total thyroidectomy and routine central lymph node dissection for $\mathrm{CNO}$ papillary thyroid cancer. Surgery. 2011 Dec;150(6): 1048-57. DOI: 10.1016/j.surg.2011.09.003; PMID: 22136820.

9. Hartl D, MamelleE, Borget I, Leboulleux S, Mirghani H, Schlumberger M. Influence of prophylactic neck dissection on rate of retreatment for papillary thyroid carcinoma. World J Surg. 2013 Aug; 37(8):1951-8. DOI: 10.1007/s00268-013-2089-3; PMID: 23677562.

10. Zhu J, Wang X, Zhang X, Li P, Hou H. Clinicopathological features of recurrent papillary thyroid cancer. Diagn Pathol. 2015 Jul 14; 10: 96. DOI: 10.1186/s13000-015-0346-5; PMID: 26168921 PMCID: PMC4501206.

11. Liu FH, Kuo SF, Hsueh C, Chao TC, Lin JD, et al. Postoperative recurrence of papillary thyroid carcinoma with lymph node metastasis. J Surg Oncol. 2015 Aug; 112(2): 149-54. DOI: 10.1002/ jso.23967; PMID: 26175314; PMCID: PMC5034820.
}

12. Yang J, Gong Y, Yan S, Shi Q, Zhu J, Li Z, et al. Comparison of the clinicopathological behavior of the follicular variant of papillary thyroid carcinoma and classical papillary thyroid carcinoma: A systematic review and meta-analysis. Mol Clin Oncol. 2015 Jul;3(4):753-764. DOI: 10.3892/ mco.2015.540; PMID: 26171175; PMCID: PMC4487034.

13. Rapoport A, Curioni OA, Amar A, Dedivitis RA. Review of survival rates 20-years after conservative surgery for papillary thyroid carcinoma. Braz J Otorhinolaryngol. 2015 Jul-Aug; 81(4):389-93. DOI: 10.1016/j.bjorl.2014.08.020; PMID: 26120098.

14. Jin BJ, Kim MK, Ji YB, Song CM, Park JH, Tae K. Characteristics and significance of minimal and maximal extrathyroidal extension in papillary thyroid carcinoma. Oral Oncol. 2015 Aug:51(8):759-63. DOI: 10.1016/j.oraloncology.2015.05.010; PMID: 26093388.

15. Scerrino G, Attard A, Melfa GI, Raspanti C, DI Giovanni S, Attard M, et al. Role of prophylactic central neck dissection in CNO-papillary thyroid carcinoma: results from a high-prevalence area. Minerva Chir. 2016 Jun; 159-67. PMID: 26046958.

16.SuhYJ, Kwon H, Kim SJ, Choi JY, LeeKE, ParkYJ, etal. Factors affecting the locoregional recurrence of conventional papillary thyroid carcinoma after surgery: a retrospective analysis of 3381 patients. Ann Surg Oncol. 2015 Oct; 22(11): 3543-9. DOI: 10.1245/s10434-015-4448-9; PMID: 25743326.

17. Kim HJ, Sohn SY, Jang HW, Kim SW, Chung JH. Multifocality, but not bilaterality, is a predictor of disease recurrence/persistence of papillary thyroid carcinoma. World J Surg. 2013 Feb;37(2):37684. DOI: 10.1007/s00268-012-1835-2; PMID: 23135422.

18. Haugen BR, Alexander EK, Bible KC, Doherty GM, Mandel SJ, Nikiforov YE. 2015 American Thyroid Association Management Guidelines for Adult Patients with Thyroid Nodules and Differentiated Thyroid Cancer: The American Thyroid Association Guidelines Task Force on Thyroid Nodules and Differentiated Thyroid Cancer. Thyroid. 2015. DOI: 10.1089/thy.2015.0020.

19.Qu N, Zhang L, Ji Q, Zhu Y, Wang Z, Shen $\mathrm{Q}$, et al. Number of tumor foci predicts prognosis in papillary thyroid cancer. BMC Cancer. 2014; 14:914. [cited 2014 Feb 12]. Available from: http:// www.biomedcentral.com/content/pdf/1471-2407-14-914.pdf

20. Lin JD, Chao TC, Hsueh C, Kuo SF. High recurrent rate of multicentric papillary thyroid carcinoma Ann Surg Oncol 2009 Sep:16(9):2609-2616. DOl: 10.1245/s10434-009-0565-7: PMID: 19533244.

21. Arora N, Turbendian H, Scognamiglio T, Wagner P, Goldsmith S, Zarnegar R, et al. Extrathyroida extension is not all equal: Implications of macroscopic versus microscopic extent in papillary thyroid carcinoma. Surgery. 2008 Dec;144(6):942-7. 